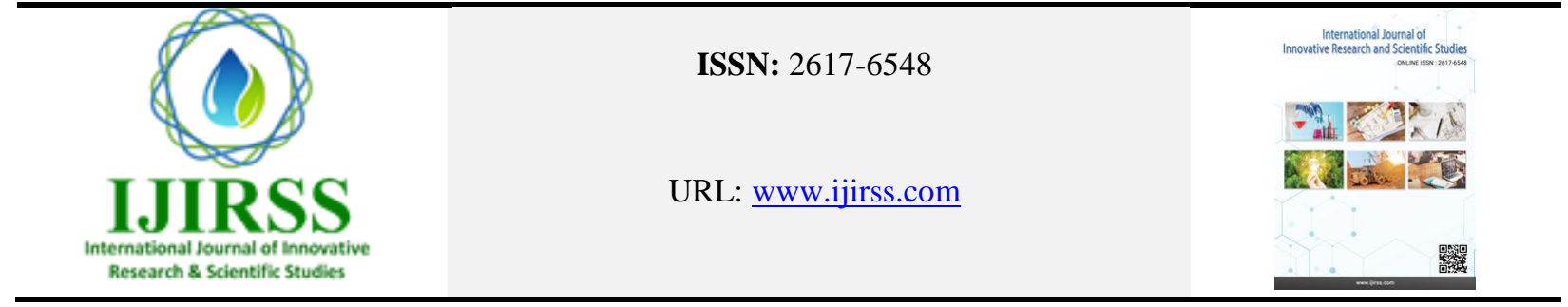

\title{
Public Awareness and their Attitudes toward Adopting Renewable Energy Technologies in Afghanistan
}

\author{
Mohammad Hamed Patmal ${ }^{1 *}$, Habiburrahman Shirani ${ }^{2}$ \\ ${ }^{1,2}$ Department of Electrical and Electronics Engineering, Kabul University, Jamal Mina 1006, Afghanistan \\ *Corresponding author: Mohammad Hamed Patmal (mhp8640@gmail.com)
}

\begin{abstract}
This research investigates the factors that potentially affect public attitudes and their adoption of renewable energy technologies for electrical energy production in Afghanistan. The study is carried out with a survey from Kabul and its neighboring provinces including Logar, Maidan Wardak, Nangarhar, Ghazni, Parwan \& Kapisa provinces. We used a random sampling process to collect data using a web-based questionnaire. The survey was well designed to highlight conveniently the public understanding, willingness, and attitudes toward adopting renewable energy technologies (RETs). The outcome of the survey is then evaluated to discover the most potential factor affecting public acceptance of RETs. The results declared that the educational level, expertise in RETs, and income of respondents are positively related, while the age of respondents is negatively related to the public willingness on the use and investment in RETs. The majority of respondents have used one type of RETs, however, $23 \%$ of respondents have not used any type of RETs. Study shows that the RETs use and access to grid electricity are reversely related, where the access is lower, the RETs use is higher and vice versa. Most of the respondents were not well informed and most disagreed with the government policies on RETs, therefore, public awareness programs on RETs and government policies are recommended. The majority of respondents were willing to invest in RETs, therefore, the government should commit itself and support private sectors to invest in RETs and take part in its development.
\end{abstract}

Keywords: Renewable Energy Technologies, Renewable Energy Sources, Public Awareness, Public Willingness, Energy Access.

DOI: $10.53894 /$ ijirss.v4i2.61

Funding: This study received no specific financial support.

History: Received: 20 January 2021/Revised: 26 February 2021/Accepted: 18 March 2021/Published: 30 March 2021

Licensed: This work is licensed under a Creative Commons Attribution 4.0 License (cc) EY

Acknowledgement: As the research was on an online survey-based study, Authors would like to take the opportunity to greatly thank the colleagues, friends, students who helped in the distribution of the survey link to the respondents and made the research fruitful.

Competing Interests: The authors declare that they have no conflict of interests.

Transparency: The authors confirm that the manuscript is an honest, accurate, and transparent account of the study was reported; that no vital features of the study have been omitted; and that any discrepancies from the study as planned have been explained.

Ethical: This study follows all ethical practices during writing.

\section{Introduction}

Afghanistan has a very low rate of consumer connection in the world to the grid [1, 2], only 29.7 percent of the population is connected to the grid [3]. The Afghanistan peak demand for electricity will increase on an average of around 7 percent per year from its current status to $18400 \mathrm{GWh}$ in 2032 [4]. A total of $978.7 \mathrm{GWh}$ of Afghanistan's electricity production is reported in 2018, while $4986.4 \mathrm{GWh}$ electricity is imported to Afghanistan in the same year which is around 
$83 \%$ of the total electricity supply at that year [5]. Total losses including transmission line, technical, and commercial were obtained to be 45 percent of the net demand in 2013 [4]. Da Afghanistan Breshna Sherkat (DABS) decreased the level of losses but still, losses are around 25 percent of the net demand [6]. Energy can perform a very essential duty in the economic and technological improvement of a nation. Several studies have found a powerful correlation between economic development and electricity consumption [7]. Afghanistan has great potential for renewable energy due to its geographical location, such as solar energy, wind energy, hydropower, and geothermal energy [8]. Afghanistan has a potential of solar radiation average of 5.5-6.5 kWh per square meter per day [9], wind energy potential around $158 \mathrm{GW}$ [4, 10], hydropower potential around 20000 to $23000 \mathrm{MW}$ [4, 11]. To achieve sustainable and reliable energy supply, all public, private sectors of energy supply and end user's involvement in renewable energy technologies is important [8]. This effective involvement can increase domestic production of energy and will decrease reliance on imported electrical energy.

As described above that besides the global interest and need toward the development of RETs for a green environment and reduction of greenhouse gases, the gap between energy demand and the domestic product is increasing, which causes more dependence on imported power from neighboring countries. However, the policies in Afghanistan are not effective, the feedback of customers is not considered in the policy developing process and are mostly developed directly from energy policymakers and utilized without the involvement of customers. This study evaluates the people's background knowledge and attitudes toward adopting renewable energy in the central regions of Afghanistan. The study is conducted on various groups of households using a questionnaire survey, which is well designed to reveal people understanding of renewable energy, their willingness to adopt it as an energy source, and factors influencing the adoption of renewable energy technologies.

This study will help the government and non-government energy policymakers to understand the level of people's awareness regarding renewable energy technologies and plan targeted public awareness policies. The same studies can be done for other regions in Afghanistan as well to specify where to invest in renewable energy technologies. This study can motivate private sectors to invest in renewable energy technologies in Afghanistan. There are a great number of studies reported worldwide on public opinions and their attitudes toward adopting renewable energy technologies. However, we could not find any study to show the people's understanding; their willingness, and attitudes toward adopting renewable energy technologies in Afghanistan. The studies reported in other parts of the world show that most of the communities are willing to use RETs. A general survey is conducted in Penisular Malaysia on renewable energy sources (RESs) and RETs, reported by Kardooni, et al. [12] the study showed that the public understanding of most Malaysians is acceptable about $\mathrm{RE}$, the cost of RETs is a great barrier to the public adoption of RETs [12]. However, they are seriously thinking about climate change. Maklad [13] publishes a report of a study on Australian acceptance of RETs, it shows that the respondents are with high positive attitudes toward domestic renewable micro electricity generation for domestic buildings considering the economic perspectives [13]. According to Ek [14] the survey-based study of Swedish individuals shows that the majority of respondents have positive attitudes to adopt wind power. The results of the study indicated that the attitudes toward adoption are decreasing with age and income [14]. A study on people's opinion on the green power market has indicated that a great rate of respondents in the UK and US are having positive attitudes to pay more for the power sources from which the environment is less adversely affected [15]. The results of a survey on public attitudes and willingness toward adopting RETs in Turkey are reported by Çelikler, and Aksan which shows that respondents had a high awareness of global warming; therefore, they had a high willingness toward RES and power stations [16]. The study on public perception of RES for South Korea is reported in 2018, which shows that the respondents' attitudes toward adopting RES are great [17]. While the respondents' educational level greatly affects the acceptance of RES. An analysis of public awareness and social acceptance of green energy is reported in 2018 individuals who participated through a web-based survey [18]. Its results show great social support for RE to reduce air pollution, GHG emissions and develop energy security. A study on energy perceptions in South Africa: An analysis of behaviour and understanding of electric water heaters indicates that its users in South Africa do not know their solar water heater consumption and the control of its efficiency, it recommends related awareness policies and discounts on costs [19]. An analysis of Canada on public attitudes toward RETs such as bio-fuels, wind, solar thermal, and solar PV shows positive attitudes and willingness from isolated and smaller communities [20].

Despite positive attitudes toward the adoption of RETs, some communities are reported with unwilling and resistant toward the development of RETs for the environment and habitat protection, the social attitudes for RET in Greece [21]. A report based on people's opinions and attitudes in Peninsular Malaysia shows a negative attitude and willingness towards the use of RETs. Participants are opposing RE projects such as wind farms [22]. The research approach is planned to answer the following research questions.

Research question 1: How much is the level of public awareness for renewable energy technologies in Afghanistan? The purpose of this research question is to evaluate the awareness level and background knowledge of participants for the use and operation of RETs.

Research question 2: How much is the level of public attitudes and willingness on renewable energy technologies in Afghanistan? This research question is to recognize the public opinions to use RETs, their willingness to adopt RETs, and their awareness of government involvement in the process of development of RETs.

Research question 3: What are the most important factors affecting the public acceptance of renewable energy technologies in Afghanistan? This research question clarifies the most significant factors affecting the acceptance of RETs. 


\section{Materials and Methods}

This study is carried out by surveying Kabul and its neighboring provinces including Logar, Maidan Wardak, Nangarhar, Ghazni, Parwan \& Kapisa provinces. The data is collected between July and September 2020. We used a random sampling process to collect data using a web-based questionnaire. Which was well designed to highlight conveniently the public understanding, willingness, and attitudes toward adopting RETs. The questionnaire was created in Google forms and distributed using various web-based channels such as Email, Messenger, and Facebook. To have only one response from each of the 353 participants, the option of limiting reply to one in online google form was used for that.

\subsection{Questionnaire Design}

Our web-based questionnaire was divided into 5 sections to deal with research questions, it included:

1. The demographic information of participants

2. Current status of energy access and use of RETs

3. Public understanding and background knowledge on renewable energy technologies

4. Public willingness and attitudes toward adopting RETs and

5. Public perception of government involvement

The first section of demographic information of participants is needed to categorize the participants from various perspectives and to help us highlight the factors affecting the participant's adoption of RETs. The second section shows the current status of energy access of participants and their use of RETs. From third to fifth, the sections are directly related to our research questions.

\section{Demographic status}

The demographic characteristics were collected through some questions with several options. The participants were asked to choose the one that best fit their characteristics including their place of residence, household income, educational level, age, and occupation.

\section{Current status of electricity access and use of RETs}

This section asked participants to answer two questions, first one is to declare that how many hours do the participants have access to electricity and the second is to show the participants' current usage of RETs.

\section{Public understanding of RETs}

This section of the questionnaire included four questions to evaluate the respondents' understanding and background knowledge of RETs. The four questions asked for the energy sources of electricity, negative impact on the environment, reduction of a power cut with the use of RETs, and improvement of the economy.

The first question of this section had options of solar, wind, hydro, coal, geothermal, nuclear, biomass/biogas, and none. This question evaluates their background knowledge of the sources of electricity. However, the remaining three questions of this section had five options of strongly agree, agree, do not know, disagree, and strongly disagree. These questions evaluate the respondents' understanding of the relative advantages of RETs.

\section{Public attitudes and willingness of RETs}

This section of the questionnaire evaluates the participants' attitudes and willingness that includes four questions. Its first question is to evaluate the willingness of all respondents to use and invest in RETs with limiting answers to three options of willing, neutral, and unwilling. The remaining three questions asked the participants about cost affection on the adoption process of RETs, time to replace/contribute to the current power grid, and the public contribution to the government for the development of the process. The answers to these three questions are limited to five options of strongly agree, agree, do not know, disagree, and strongly disagree. These questions can describe the respondents' attitudes toward the adoption of RETs.

\section{Public perception of government involvement}

In this section, the respondents were asked four questions on government involvement with choosing one of the five options of strongly agree, agree, do not know, disagree, and strongly disagree. The questions were on government support of the public to use RETs, willingness to use the public budget for the development of RETs, the commitment of the government to invest in RETs, and public encouragement by the government to use RETs. These questions can evaluate the participants' perception of government in the development process of RETs.

\subsection{Factor Selection in adopting RETs}

We have studied the willingness to adopt RETs versus sociodemographic characteristics of participants and found some positive/negative correlations. The positive/negative correlations of sociodemographic characteristics such as household income, educational level, occupation, age, and expertise versus willingness to use and invest in RETs are described with graphical representations.

\section{Results and Discussions}

\subsection{Demographic Characteristics}

Totally 353 individuals participated in the survey, from which $48.2 \%$ were from Kabul and around $10 \%$ from each of the neighboring provinces, as shown in Table 1. The reason behind the higher frequency in Kabul and lower in other provinces is the access of people to the internet. As Kabul is the capital of Afghanistan, people have more access to the internet compare to other provinces and rural areas. 
Table-1.

Province based frequencies of participants.

\begin{tabular}{l|l|c|c}
\hline \multirow{4}{*}{ Characteristics } & Frequency & Percentage $(\boldsymbol{\%})$ \\
\hline \multirow{5}{*}{ Area } & Kabul & 170 & 48.2 \\
\cline { 2 - 4 } & Logar & 34 & 9.6 \\
\cline { 2 - 4 } & Maidan Wardak & 44 & 12.5 \\
\cline { 2 - 4 } & Ghazni & 35 & 9.9 \\
\cline { 2 - 4 } & Nangarhar & 37 & 10.5 \\
\cline { 2 - 4 } & Parwan, Kapisa & 33 & 9.3 \\
\hline Total & Kabul \& its neighboring provinces & 353 & 100 \\
\hline
\end{tabular}

Individuals with various categories of household income have participated in our survey. It includes a very low income of less than 128 USD (10000 AFN) up to a high income of up to more than 638 USD (50000 AFN). We were trying to keep the balance between all ranges of household income, but as people living in Afghanistan are in low income, we divided the respondents into several ranges of household income as shown in Table 2. The majority of the respondents $(56.6 \%)$ are having a household income of less than 383 USD (30000 AFN) (see Table 2).

Table-2.

Income-based frequencies of participants

\begin{tabular}{|c|c|c|c|}
\hline & Characteristics & Frequency & $\begin{array}{c}\text { Percentage } \\
(\%)\end{array}$ \\
\hline \multirow{7}{*}{$\begin{array}{l}\text { Household } \\
\text { Income }\end{array}$} & $>638$ USD & 66 & 18.7 \\
\hline & $510-638$ USD & 38 & 10.8 \\
\hline & $383-510$ USD & 49 & 13.9 \\
\hline & $255-383$ USD & 69 & 19.5 \\
\hline & $128-255$ USD & 65 & 18.4 \\
\hline & $<128$ USD & 66 & 18.7 \\
\hline & Total & 353 & 100 \\
\hline
\end{tabular}

Table 3 Shows the age and occupation characteristics versus frequencies of respondents. We can see that individuals of several ages from 18 to 55 years have participated in the survey. Since our survey was web-based and mostly the young generation is using the internet, therefore the highest rate of respondents are youths from 18 to 25 years $(52.7 \%)$. The Table 3 shows that respondents are from various occupational characteristics as government employees, private sectors, self-employed, students, and unemployed. The highest rate is of government employees and the lowest is of selfemployed, while we had $4 \%$ of people who did not want to share their occupational characteristics.

Table-3.

Age and occupation-based frequencies of participants.

\begin{tabular}{|c|c|c|c|}
\hline & Characteristics & Frequency & Percentage $(\%)$ \\
\hline \multirow{4}{*}{ Age } & $18-25$ & 186 & 52.7 \\
\hline & $26-35$ & 140 & 39.7 \\
\hline & $36-45$ & 20 & 5.7 \\
\hline & $46-55$ & 6 & 1.7 \\
\hline \multirow{7}{*}{ Occupation } & Government & 105 & 29.7 \\
\hline & Private Sector & 76 & 21.5 \\
\hline & Not applicable & 14 & 4 \\
\hline & Self-employed & 23 & 6.5 \\
\hline & Student & 87 & 24.6 \\
\hline & Unemployed & 47 & 13.3 \\
\hline & Total & 353 & 100 \\
\hline
\end{tabular}

The survey has received responses from individuals with various educational levels from some level of high school up to Ph.D., where the highest rate is of bachelor degree that is $48.2 \%$ as shown in Table 4 . 
Table-4.

Education-based frequencies of participants.

\begin{tabular}{|c|c|c|c|}
\hline & Characteristics & Frequency & Percentage $(\%)$ \\
\hline \multirow{8}{*}{ Education } & Ph.D. & 6 & $1.7 \%$ \\
\hline & Master's Degree & 60 & $17 \%$ \\
\hline & Bachelor's Degree & 170 & $48.2 \%$ \\
\hline & Some college-level / No Degree & 89 & $25.2 \%$ \\
\hline & Tech/Vocational Institute graduate & 4 & $1.1 \%$ \\
\hline & High school graduate & 18 & $5.1 \%$ \\
\hline & Some High school level & 6 & $1.7 \%$ \\
\hline & Total & 353 & 100 \\
\hline
\end{tabular}

\subsection{Current status of electricity access and use of RETs}

The result of our survey depicted in Figure 1 shows that a total $52 \%$ of respondents have access to electricity for $>12$ hrs. The electricity access rate for more than 12 hours on daily basis is the highest in Kabul city for which it approaches 68 $\%$, however, this rate decreases to the other neighboring provinces such as Maidan Wardak to nearly $32 \%$ and Ghazni to about $20 \%$ which is the lowest access among other surveyed provinces.

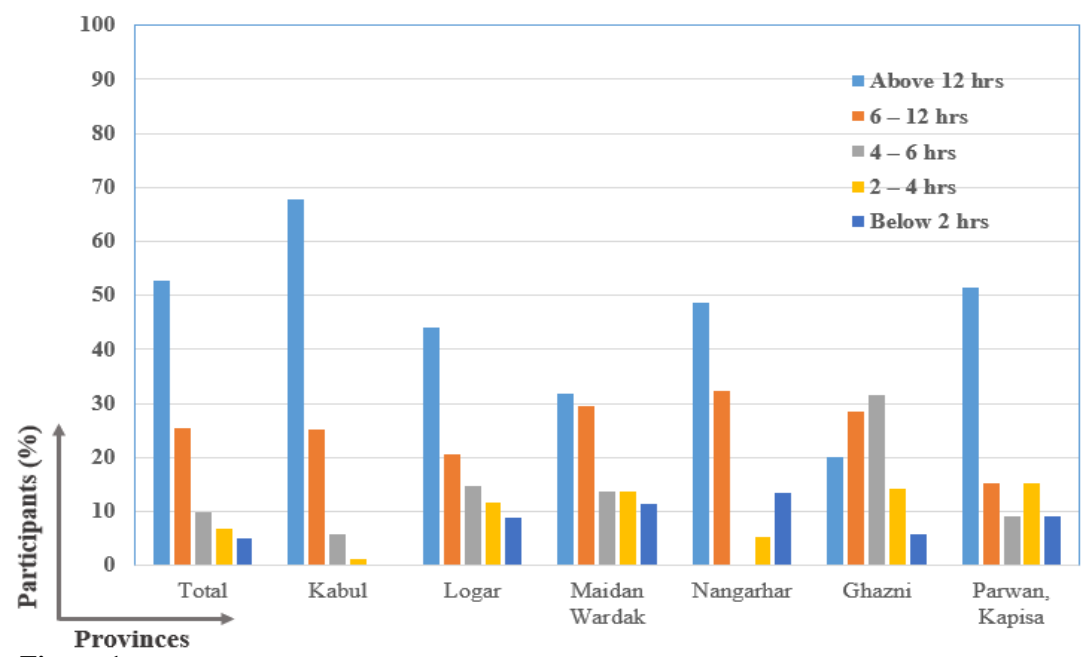

Figure-1.

Electricity access percentage of participants per 24 hours.

The participants' rate of current use for RETs is described in Figure 2. It shows that about $49 \%$ of respondents have experienced solar, while $23 \%$ have not experienced any type of RETs yet. The figure shows that the rate of RETs use in rural areas is higher compared to central areas. We have found earlier that electricity access is highest in Kabul and the lowest for Ghazni, here we can see Ghazni province as the highest user of RETs that reaches $71 \%$ and Kabul the lowest user that reaches $35 \%$. Therefore, we found that electricity access has a reverse relation with RETs use in Afghanistan.

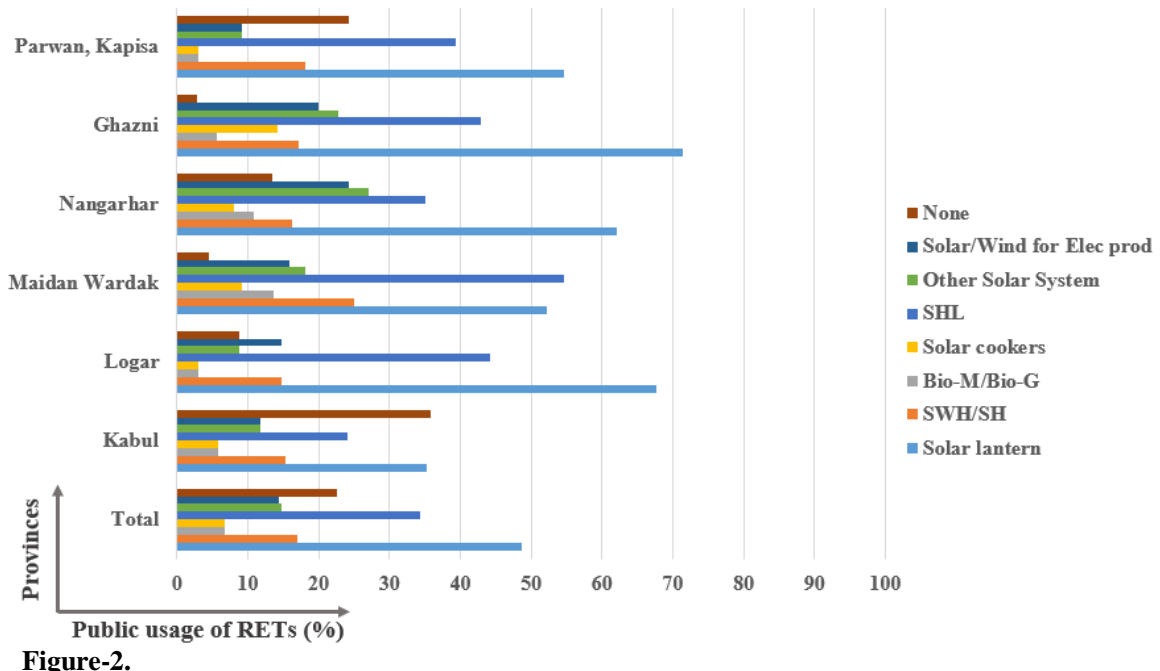

Figure-2.

Participants' usage percentage of renewable energy technologies. 


\subsection{Public understanding of RETs}

The result of public understanding of electricity sources is drawn in Figure 3. It shows that people have Great knowledge of hydro-energy, for which $89 \%$ of all respondents think that they can generate electricity from hydropower, while this rate is $76 \%$ for solar energy and wind is $56 \%$. The rate of respondents' understanding of other RESs such as biomass/biogas and geothermal are very low that reach $20 \%$ and $13 \%$ respectively.

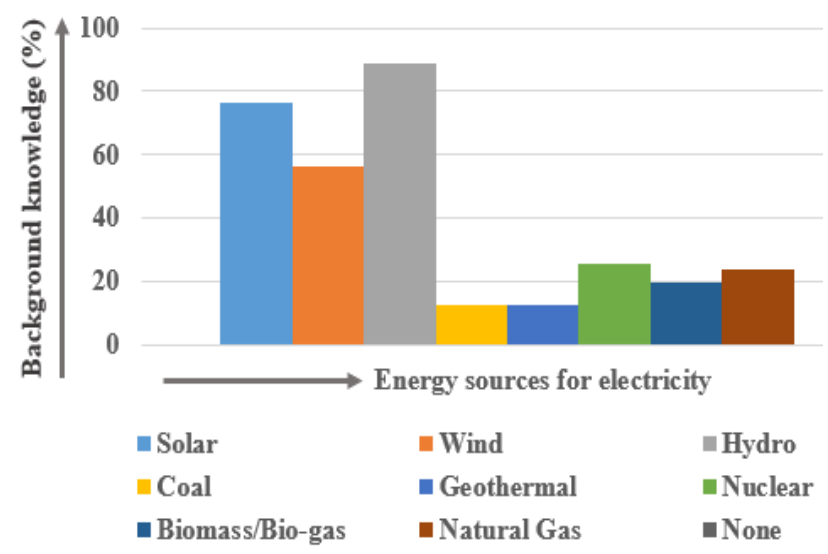

Figure-3.

Background knowledge of participants.

Figure 4 shows respondents' understanding of RETs, it describes that $77 \%$ of participants do agree that RETs have a less negative impact on the environment compared to fossil fuels. Around $84 \%$ of respondents do agree that the use of RETs will decrease power cut and $96 \%$ of them thinks that its use will improve the economy. We can say that nearly $23 \%$ of participants are not well aware of RETs operation and its relative advantages.

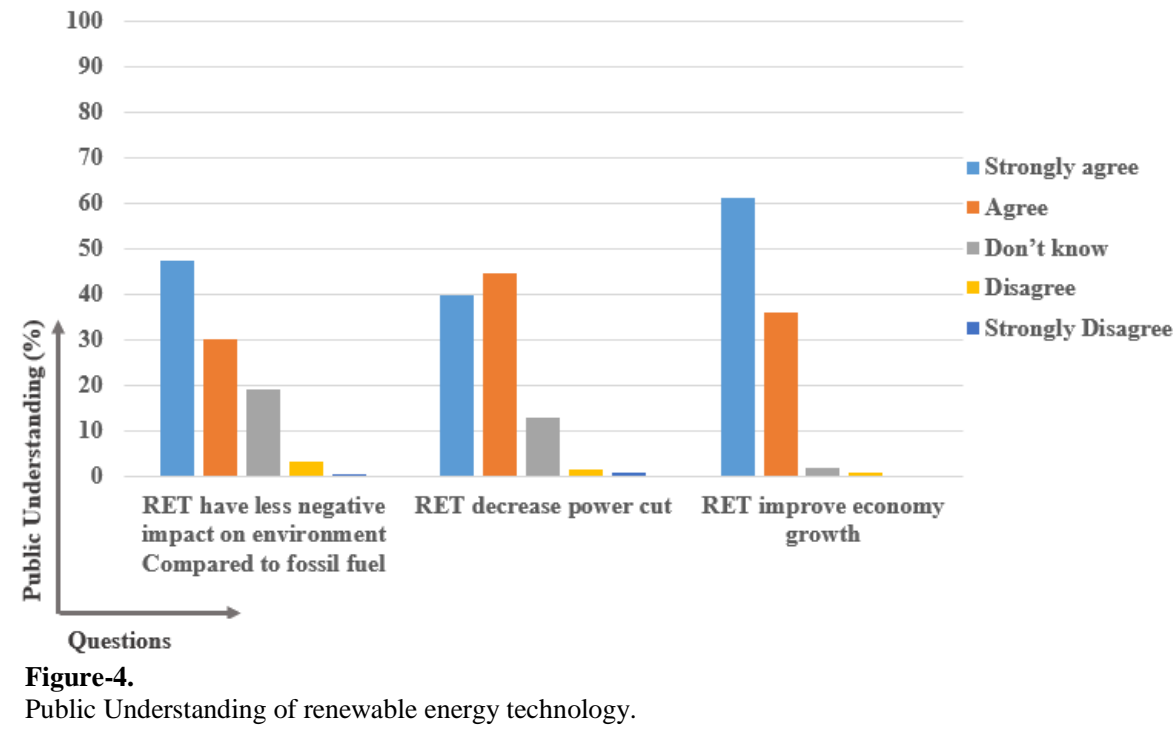

\subsection{Public willingness and attitudes toward adoption of RETs}

The results of participants' responses show that $94 \%$ of respondents think that cost affects their attitudes toward adopting RETs and the same rate of respondents think that contribution of all residents in the development process of RETs to the government is needed. We found that majority of respondents are thinking that RETs will take a long time to contribute or replace the current power grid, while we found the same rate as earlier that $23 \%$ of participants have responded that they are not well informed of RETs operation and development process (see Figure 5).

\subsection{Public perception of government involvement}

The result of respondents' perception of government policies and public support as drawn in Figure 6 shows that only $30 \%$ of them do agree or aware, while $70 \%$ of them are not aware, disagree, or even strongly disagree. This shows that majority of the people are not aware of government policies and support for the development of the RETs process in Afghanistan. A great number of respondents $88 \%$ claim that the government is investing very slowly in the RETs development process, while $77 \%$ of respondents agree with the government to invest the public budget in the RETs development process. The result shows that $98 \%$ of participants request that government must encourage the public as well to use RETs. 


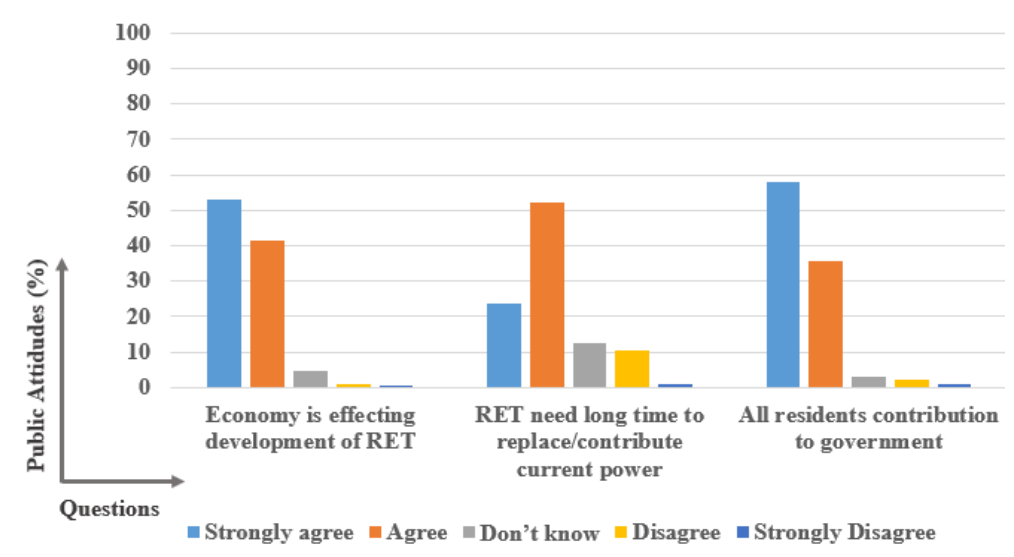

Figure-5.

Attitudes toward adoption of RET.

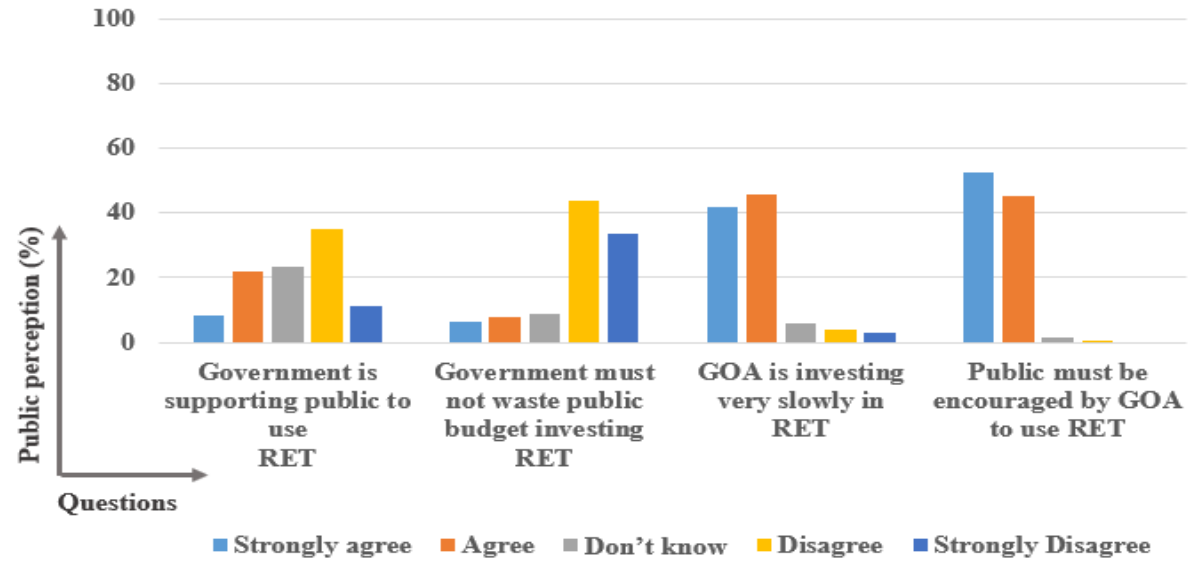

Figure-6.

Public perception of government involvement in RET development.

\subsection{Factor selection in adopting RETs}

The effect of household income on willingness to adopt RETs is drawn in Figure 7. It shows that household income has a positive relationship with willingness to use/invest in RETs. In other words, unwillingness and neutrality are the highest $24 \%$ for the income of < 128 USD however, it is decreasing as income is increasing that reaches $6 \%$ for income of $>638$ USD which is the lowest rate.

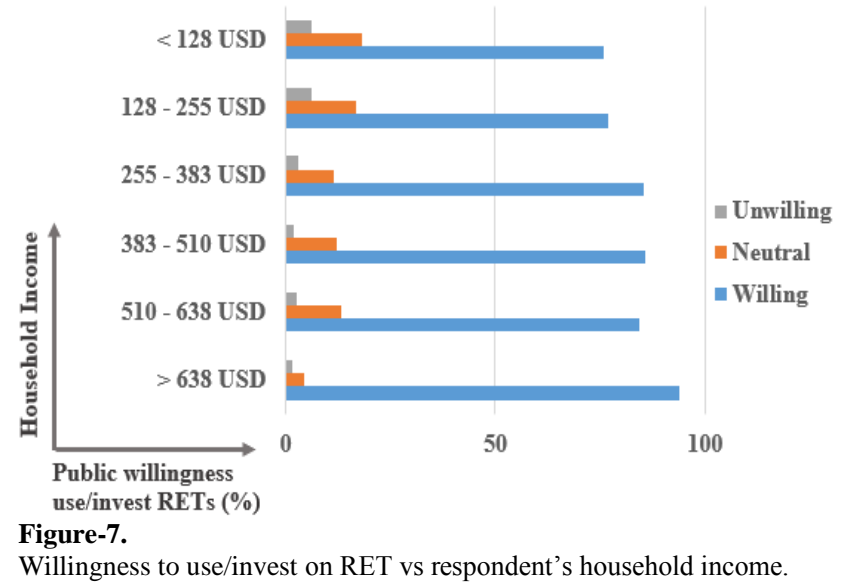

The effects of willingness to use/invest on RETs versus educational level are represented in Figure 8 . For the lowest educational level of some level of High School, we received the highest neutrality as 33\%, while this neutrality and unwillingness are decreasing as the educational level is increasing and approaches zero for Ph.D. level. 


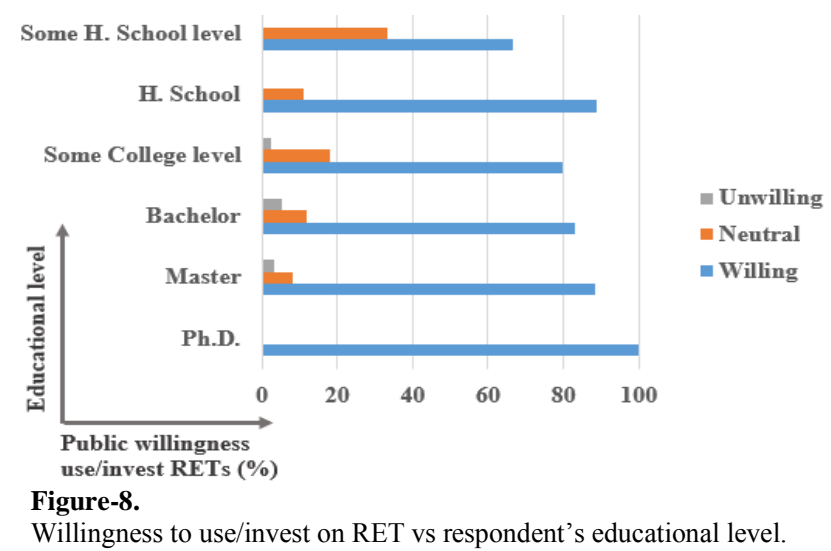

Figure 9 shows the willingness to use/invest in RETs according to the occupation of participants. It describes that the highest neutrality and unwillingness of $21 \%$ is for respondents who did not give their occupational details (not applicable). The lowest rate of unwillingness and neutrality is of government employees, which is around $12 \%$.

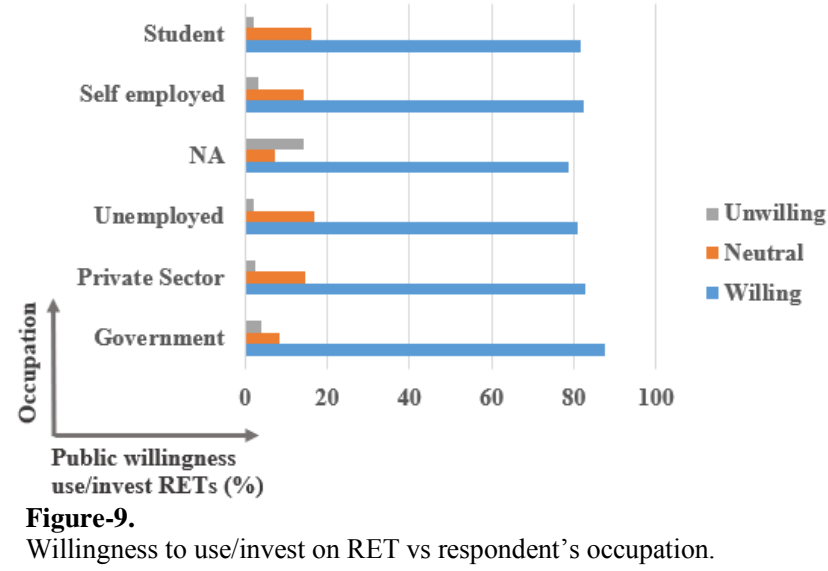

The results of age effects on willingness to use/invest in RETs are represented in Figure 10. It shows that age is positively related to the willingness to use/invest in RETs. The lowest willingness is of the age between 46 to 55 years, which is $67 \%$ of respondents, and as the age is decreasing the willingness is increasing, while the highest rate is for the age of participants between 26 to 35 years, which is $86 \%$.

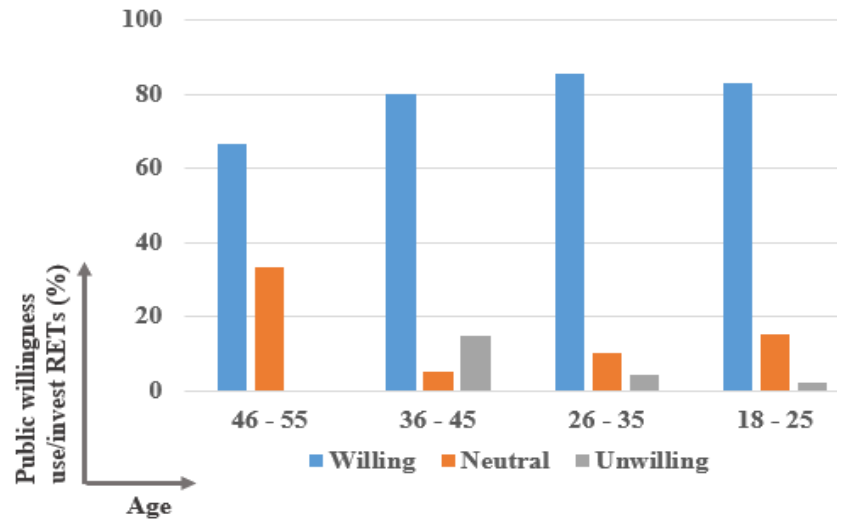

Figure-10.

Willingness to use/invest on RET vs respondent's age.

The willingness to use/invest in RETs versus the expertise level of respondents is described graphically in Figure 11. Here the level (5) of expertise is the highest, while (1) is the lowest level of knowledge on RETs. Fig. 11 says that the expertise level of participants is directly related to the willingness, as the expertise level is increasing the level of willingness is increasing. The lowest level of willingness of respondents is for the lowest expertise level (1) that is $67 \%$, while the highest is for level (4) here not for level (5). The reason is that the participants with expertise level (5) had a little higher number of individuals with the lowest household income of $<128$ USD and in between 255 to 383 USD and a higher rate of participants' age, which were not for the case of level (4). 


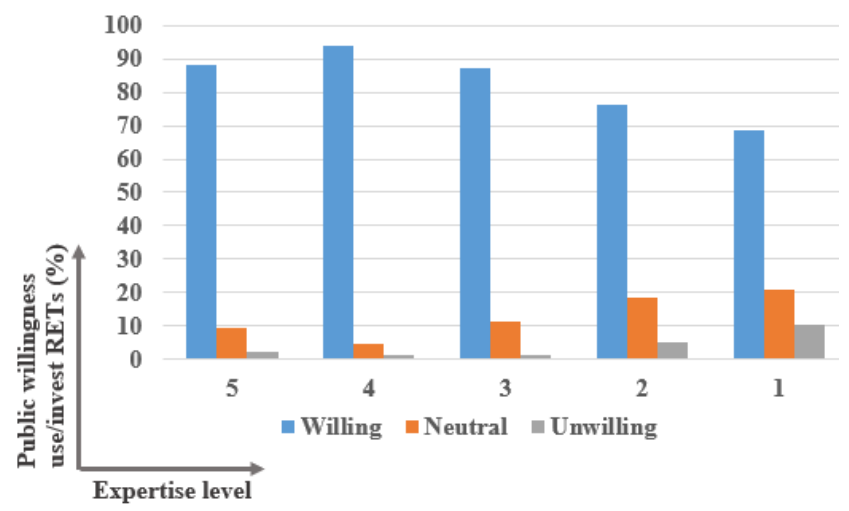

Figure-11.

Willingness to use/invest on RET vs respondent's expertise levels (5 is expert and 1 is no knowledge).

\section{Conclusion}

As we mentioned in the introduction part of this study that near $30 \%$ of the population of Afghanistan is connected to the grid, while this connection rate is the lowest in rural areas even it approaches zero for some places, and this rate is the highest for urban and central areas. Kabul with the highest rate of grid connection is found to suffer from several power cuts per day and $32 \%$ of respondents replied with access to grid electricity of fewer than 12 hours. People in rural areas have low access to electricity and connection to the grid; therefore, results show that areas with low access to grid electricity are using RETs as alternative electricity sources. We can conclude that access to electricity is reversely related to the use of RETs. Our results show that majority of people have enough knowledge of hydro, solar, and wind as electrical energy sources. The awareness for biomass/biogas and geothermal as the energy source for electricity generation was found to be very low, while biomass is greatly available in rural areas of Afghanistan. Besides that, we have several potential points of geothermal energy. The use of available biomass, biogas, and geothermal energies can help reduce greenhouse gas emissions and improve rural electrification and the economy of Afghanistan. RETs use of participants was great; their majority were using one type of RETs. The highest rate of usage was the technology of solar energy, but there is still a high number of respondents not well informed of RETs use and operation. The highest rate of participants are claiming that their contribution to the government is a need in the development process of RETs, however, these respondents think that cost is the greatest challenge to their adoption and usage of RETs. The analysis of respondents' sociodemographic characteristics and willingness to adopt RETs clears that there are factors that directly affect the willingness of respondents. The education, expertise on RETs, and income are positively related, while the age of participants is negatively related to the willingness of respondents the use and invest in RETs. A great number of respondents are not aware of the policies and support of the government to the public for the development of RETs. The majority of respondents even disagree with the policies of the government and claim their strong disagreement that the government is not supporting them to use and invest in RETs. Respondents show their agreement that the government can use the public budget to develop RETs.

\section{Recommendations}

As we found that some of the respondents are not well informed about RETs, especially on biomass/biogas, geothermal and government policies on RETs, therefore, more public awareness programs on RETs and government policies are needed. Besides the awareness programs, the government must encourage and support the public to use and invest in RETs. A very high rate of people was claiming that the government is investing very slowly on RETs since currently our electricity for more than $83 \%$ is imported from neighboring countries. To decrease the dependence on imported power, the government should commit to investing in RETs. The majority of participants and youth were found with a high rate of willingness to use and invest in RETs, therefore the government of Afghanistan should support private sectors to invest and operate in the RETs development process.

Since the data on RETs for Afghanistan is very rarely reported, this data can be very updated and very close to reality. As this study is based on Kabul and its neighboring provinces, the same studies can be performed for other regions, especially in rural areas of the country to report rural attitudes toward adopting RETs. While doing rural studies, it is recommended to do the off-line (paper-based) survey as the web-based survey is not applicable for most of the rural areas of Afghanistan.

\section{References}

[1] D. Gencer, J. Irving, P. Meier, R. J. Spencer, and C. Wnuk, Islamic republic of Afghanistan energy security trade-offs under high uncertainty: Resolving Afghanistan's power sector development dilemma. Washington, D.C: World Bank Group, 2016.

[2] India Smart Grid Forum, Study on development of roadmap for implementation of smart grid-concepts, practices and technologies in SAARC Region, (December 2018): SAARC Energy Center, 2018.

[3] World Bank Group, Afghanistan renewable energy development issues and options. Washington D.C: World Bank Group, 2018.

[4] Fichtner, Islamic of Afghanistan: Power sector master plan. Stuttgart: Fichtner, 2013.

[5] National Statistics and Information Authority (NSIA), "Yearbook Afghanistan statistical 2018-19," 2019. 
[6] Special Inspector General for Afghanistan reconstruction, "Afghanistan's energy sector: USAID and DOD did not consistently collect and report performance data on projects related to kajaki dam and concerns exist regarding sustainability, SIGAR 19-37 Audit Report," 2019.

[7] Y. O. Akinwale, I. O. Ogundari, O. E. Ilevbare, and A. O. Adepoju, "A descriptive analysis of public understanding and attitudes of renewable energy resources towards energy access and development in Nigeria," International Journal of Energy Economics and Policy, vol. 4, p. 636, 2014.

[8] R. Rostami, "Renewable and sustainable energy reviews," 2016.

[9] M. Nadeem, "Energy resources in Afghanistan and measures to improve for sustainable development," Journal of Sustainable Energy Engineering, vol. 2, pp. 1-11, 2011.

[10] Ministry of Energy and Water, "Afghanistan Wind Energy information," 2007.

[11] Ministry of Energy and Water, Treatise on the power system of Afghanistan, Ministry of Energy and Water. Kabul, Afghanistan: Islamic Republic of Afghanistan, n.d.

[12] R. Kardooni, S. B. Yusoff, F. B. Kari, and L. Moeenizadeh, "Public opinion on renewable energy technologies and climate change in Peninsular Malaysia," Renew. Energy, vol. 116, pp. 659-668, 2018. Available at: https://doi.org/10.1016/j.renene.2017.09.073.

[13] Y. Maklad, "Australia is highly motivated to focus on domestic renewable micro electricity generation for domestic buildings economy wise," International Journal of Energy Economics and Policy, vol. 4, pp. 373-379, 2014.

[14] K. Ek, "Public and private attitudes towards "green" electricity: The case of Swedish wind power," Energy Policy, vol. 33, pp. 1677-1689, 2005.

[15] S. L. Batley, D. Colbourne, P. D. Fleming, and P. Urwin, "Citizen versus consumer: challenges in the UK green power market," Energy Policy, vol. 29, pp. 479-487, 2001.

[16] D. Celikler and Z. Aksan, "The opinions of secondary school students in Turkey regarding renewable energy," Renew. Energy, vol. 75, pp. 649-653, 2015.

[17] J. Kim, S. Y. Park, and J. Lee, "Do people really want renewable energy? Who wants renewable energy?: Discrete choice model of reference-dependent preference in South Korea," Energy Policy, vol. 120, pp. 761-770, 2018. Available at: https://doi.org/10.1016/j.enpol.2018.04.062.

[18] C. Bhowmik, S. Bhowmik, and A. Ray, "Social acceptance of green energy determinants using principal component analysis," Energy Policy, vol. 160, pp. 1030-1046, 2018. Available at: https://doi.org/10.1016/j.energy.2018.07.093.

[19] P. Nel, M. J. Booysen, and B. Van der Merwe, "Energy perceptions in South Africa: An analysis of behaviour and understanding of electric water heaters," Energy for Sustainable Development, vol. 32, pp. 62-70, 2016. Available at: https://doi.org/10.1016/j.esd.2016.03.006.

[20] D. Bush and P. Hoagland, "Public opinion and the environmental, economic and aesthetic impacts of offshore wind," Ocean \& Coastal Management, vol. 120, pp. 70-79, 2016.

[21] J. K. Kaldellis, "Social attitude towards wind energy applications in Greece," Energy Policy, vol. 33, pp. 595-602, 2005.

[22] R. Kardooni, S. B. Yusoff, and F. B. Kari, "Renewable energy technology acceptance in Peninsular Malaysia," Energy Policy, vol. 88, pp. 1-10, 2016. Available at: https://doi.org/10.1016/j.enpol.2015.10.005. 